\title{
Hospitalidad nupcial y escritura posmoderna: la poesía mística de Christophe Lebreton
}

\author{
CeCilia AvenatTi de PALUMBO* \\ Pontificia Universidad Católica Argentina (Argentina) \\ ceciliapalumbo52@gmail.com
}

\begin{abstract}
Resumen
El propósito de este artículo es presentar a Christophe Lebreton (1950-1996) monje, poeta y mártir en Argelia como una figura que representa una renovación del lenguaje con el que se dice el misterio de Dios hecho experiencia humana. La tesis que sostenemos es que su escritura poética, de rasgos posmodernos, dice a Dios de un modo actualizado tanto por su forma como su contenido, en el que destacan la hospitalidad y la nupcialidad.

Palabras clave: Christophe Lebreton, hospitalidad, nupcialidad, poesía mística, posmodernidad.
\end{abstract}

\section{Nuptial hospitality and postmodern writing in Christophe Lebreton's mystic poetry}

\section{Abstract}

The purpose of this article is to present Christophe Lebreton (1950-1996) monk, poet and martyr in Algeria, as a figure that represents a renewal of language with which the mystery of God turned into buman experience, is expressed. The thesis we maintain is that his poetic writing, of postmodern traits, names God in an updated way both in form and content, in which hospitality and nuptiality stand out.

Key words: Christophe Lebreton, hospitality, nuptiality, mystic poetry, postmodernity.

\footnotetext{
* Doctora en Letras. Profesora Titular Ordinaria de Estética en la Facultad de Filosofía y Letras y Facultad de Teología de la Pontificia Universidad Católica Argentina. Ha dirigido libros colectivos y publica con regularidad en revistas científicas. Entre sus libros propios se destacan: La literatura en la estética de Hans Urs von Balthasar. Figura, drama y verdad (2002); Lenguajes de Dios para el siglo XXI. Estética, teatro y literatura como imaginarios teológicos (2007); Caminos de espiritu y fuego. Mistica, estética, y poesía (2011); Presencia y ternura. La metáfora nupcial (2014). Ha dedicado a la figura de Christophe Lebreton varios artículos y dos libros: El sediento amante. Nupcialidad, pensamiento y lenguajes (2016); La casa en el puente. Christophe Lebreton, huésped de fronteras (2017).
} 
INTRODUCCIÓN ${ }^{1}$

"Algo en mi carne ha tomado forma de escritura"

(Lebreton, 2002: 37).

En mayo de 1996 la noticia del asesinato de siete monjes cistercienses ocurrido durante la sangrienta guerra civil argelina conmovió a la opinión pública. A partir de entonces, sus vidas silenciosas y anónimas salieron a la luz despertando el interés de historiadores, teólogos, artistas, dramaturgos, cineastas. Mártires de la intolerancia y la violencia, su testimonio de diálogo y de paz los convierte en íconos de la cultura del encuentro. El testamento del abad Christian de Chergé se convirtió en un signo de esperanza, cuya fuerza proviene de la certeza de que la comunión y el perdón son posibles como acción del "gozo secreto del Espíritu", que consiste en "restablecer la semejanza, jugando con las diferencias" (Olivera \& Silveyra, 1997: 11-13). Recientemente, el papa Francisco ha decretado su beatificación proponiéndolos al mundo actual como figuras paradigmáticas de santidad vivida en comunidad (Francisco, 2018: n.141).

Uno de ellos era poeta, se llamaba Christophe Lebreton (Blois-Francia, 1950 - Argelia 1996). Varias cajas de manuscritos se encontraron entre sus pertenencias luego de la muerte: diarios, homilías, reflexiones teológicas, dibujos y centenares de poemas. Toda su vida está dicha en el poema "En verdad":

VIVIR de

$$
\begin{array}{ll}
\text { esto } & \\
& \text { 'yo quiere } \\
& \text { 'yo te }
\end{array}
$$

hoy (Lebreton, 1997: 13; 2017, 22)

Su figura como mártir y escritor fue recogida por Mirella Susini (2008) y su teología del don fue estudiada por Marie-Dominique Minnasian (2009; 2014): estas investigaciones, realizadas desde la perspectiva del martirio y la espiritualidad, constituyen los aportes más relevantes publicados

$1 \quad$ El artículo que aquí presentamos fue elaborado sobre la base de dos conferencias inéditas, a saber: "Hospitalidad y escritura nupcial en la poesía mística de Christophe Lebreton", en Congreso Internacional La palabra y el misterio. Resonancias de la mistica cristiana en la poesía contemporánea de Baudelaire hasta nuestros días, Santiago de Chile: Universidad de los Andes - Instituto de Literatura, 6- 8 de octubre de 2016; "Hospitalidad y concordia. El tópico medieval del cubiculum cordis en la escritura poética de Christophe Lebreton", en XII Jornadas Nacionales de Filosofía: Edificar la concordia en el pensamiento medieval. Buenos Aires; Academia Nacional de Ciencias de Buenos Aires, del 18 al 21 de abril de 2017. 
al día de hoy ${ }^{2}$. A pesar de que sus poemas y su diario se publicaron poco tiempo después de su muerte (Lebreton: 1997; 1999), los estudios literarios no se han ocupado aún de su obra. Las investigaciones, que he venido desarrollando sobre el carácter poético místico de su escritura, intentaron cubrir este vacío. En continuidad con las publicaciones ya realizadas, ${ }^{3}$ en el presente artículo me propongo dos objetivos: primero, presentar las notas de estilo que fundamenten la validación de la poesía de Christophe Lebreton como escritura posmoderna; segundo, considerar la hospitalidad nupcial como clave hermenéutica a fin de situar su obra en el horizonte posmoderno de la alteridad.

Para lo cual, en primer lugar, ubicaré la figura y la obra de C. Lebreton en el contexto de la vanguardia poética caracterizada por la dinámica de escritura y alteridad, a fin de mostrar que su actualidad y atracción radica justamente en la forma posmoderna adoptada. En segundo lugar, presentaré la hospitalidad del silencio como arca de una escritura que, más allá de la renovación de recursos formales, busca alcanzar la transfiguración ética. En tercer lugar, en base a las notas de alteridad y hospitalidad descriptas, lo postularé como hito fundador de un estilo de poesía mística nupcial en la que el clásico tópico del cubiculum cordis ha devenido en escritura hospitalaria.

\section{ESCRITURA POÉTICA Y ALTERIDAD}

C. Lebreton perteneció a la generación de posguerra y, por tanto, vivió tiempos de rupturas y de cambios de paradigma, cuyas consecuencias llegan hasta nuestros días en variedad de formas. Su interés por establecer la justicia y la paz en un mundo convulsionado lo llevó a rebelarse ante tradiciones e instituciones, como lo hicieron muchos de los jóvenes de entonces. En el siguiente texto autobiográfico describe, en breves trazos, el camino que lo condujo desde Francia a Argelia, desde la universidad al monasterio, a través de la experiencia de una llamada de amor personal de Dios, a la que respondió eligiendo vivir entre los más pobres hasta llegar a la comunión con todos los hombres en Jesús:

En el '68 tomé mi libertad... ipensaba yo! Abandoné toda práctica religiosa y eso hasta el fin de mis estudios. En los campamentos de Emaús tomo

2 Para una bibliografía secundaria sobre los monjes del Monte Atlas en su conjunto y sobre Christophe Lebreton en particular, ver: Avenatti \& Bertolini (2017a).

3 Las publicaciones realizadas sobre la obra poética de C. Lebreton desde el punto de vista de la estética teológica y la nupcialidad constituyen un antecedente sobre el que se basa el enfoque del presente artículo (Avenatti: 2014; 2016a; 2016b; 2016c; Avenatti \& Bertolini: 2015a; 2015b; 2016; 2017a; 2017b). 
conciencia de que hay pobres, y que a partir de ese momento no puedo vivir si olvido este hecho enorme, y que la felicidad no puede ser encontrada sin ellos. Esa elección por una vida de servicio, muy rápidamente debía conducirme hacia una Persona: acogía sin saberlo ese otro hecho inmenso de que existe Jesucristo... un día dije "sí". Descubro al padre Foucauld, cuya vida y escritos han despertado en mí el deseo loco de seguir a Jesús, de amarlo, y por lo tanto de parecerme a él. Luego entró al servicio militar... en Argelia. Subí varias veces a Nuestra Señora de Atlas, y me gustó esta comunidad sin brillo, simple y muy verdadera: hombres que se obstinan humilde y apaciblemente a testimoniar que Dios vale la pena, que demos juntos la vida por Él, para rezarle, adorarle, acoger las Bienaventuranzas... y aprender así a amar, a amar hasta el extremo de lo cotidiano. Elegí entonces la vida en el Atlas (Lebreton, 1997: 14-15; 2017: 23-24).

Mientras estudiaba derecho y leía a sus contemporáneos -a Simone Weil (Lebreton, 2002: 103. 218) y Emmanuel Lévinas (Lebreton, 1997: 16; 2017, 25; 2002: 243. 248) entre otros-, en lo secreto de su habitación interior o cubiculum cordis oyó la voz de Dios que le susurró ese "Yo te amo" que cambiaría su vida para siempre: "Tu yo te amo un día se me apareció. De ello aun no me he repuesto" (Lebreton, 2002: 26). La sed de relación y la conciencia de fragilidad fueron, desde entonces, "su" herida de amor. A esta experiencia retornará una y otra vez a lo largo de su vida de monje trapense: "En el fondo, vuelvo siempre a este te amo dicho un día en Tours... y en esa expresión se centra mi vida; estoy sobrepasado, desbordado, excedido" (Lebreton, 2002: 119). Permanecer en Argelia fue su respuesta al amor de Dios así manifestado. Por eso eligió estar en los márgenes, entre los pobres, los extranjeros, los hostiles y los faltos de amor, a los que buscó hospedar en su corazón en bodas: aquí se encuentra la fuente de su fe y de su poesía:

A la hora de Nombrarte, nuestro lenguaje es siempre impuro. Esa fue la experiencia en mi cuarto de estudiante vigilante en Tours. Ni una sola imagen de Dios. Pero este te amo desgarrando mi carne: acto de confianza perdida (Lebreton, 2002: 151).

Fue precisamente en la "casa del Islam", tierra extranjera y empobrecida, donde tras un proceso de donación progresiva, entregó su vida el 21 de mayo de 1996, junto a seis de sus hermanos de la abadía del Monte Atlas (Olivera \& Silveyra, 1997; Olivera, 2011). Apenas transcurrido un año, sus manuscritos comenzaron a ser publicados: primero, la poesía, reunida en volumen bajo el título Aime jusqu'au bout du feu (Lebreton, 1997; 2017); luego, el diario del último tiempo, Le souffle du don (1999; 2002); 
finalmente, sus homilías (Lebreton, 2009, 2010a; 2010b). Uno de los prefacios presenta su vida como "un largo poema de amor":

Las homilías del padre Christophe, como sus poemas, tenían un estilo que era totalmente propio, haciendo una llamada a la sensibilidad, a la imagen, al sentimiento. Este sello personal lo volvemos a encontrar en la redacción de su diario durante el tiempo que va del 8 de agosto de 1993 al 19 de marzo de 1996: últimos años de nuestra vida de comunidad en Tibhirine antes del drama que la interrumpió brutalmente la noche del 26 al 27 de marzo de 1996. Christophe tiene una manera particular de exponer los hechos de cada día que no resulta anodina, neutra o fría: su relato está habitado, tiene alma, la suya (Veilleux, 2002: 10).

En su escritura reconocemos, pues, un doble origen: por un lado, la hospitalidad del silencio y el secreto del corazón enamorado, y por otro lado, su indeclinable compromiso con la vida de los hombres de la calle asediados por la pobreza y la violencia, frutos ambos de la desmesura del poder. En este contexto personal y social, la nupcialidad y la hospitalidad confluyeron en la gestación de una escritura que buscó expresar el dinamismo existencial de donación y recepción en el lenguaje de la poesía.

$\mathrm{Al}$ introducir su perfil de escritor, Didier destaca que "son poemas para ver tanto como poemas para oír", "ver el dibujo significativo de las palabras, su enraizamiento o su vuelo en la página", "una verdadera geografía, tanto para contemplar desde lo alto, como visto desde el cielo en visión global, como para leer siguiendo el sendero de las frases" (Lebreton, 1997: 44; 2017: 54). ¿De dónde proviene este modo peculiar de escribir? La palabra y el dibujo estuvieron unidos desde el comienzo de la escritura. Sabemos que más allá de los orígenes pictográficos e ideográficos de las escrituras antiguas (cuya proximidad con la pintura conservan aún la escritura china y árabe), lo cierto es que el proceso de alfabetización en occidente alejó el signo lingüístico de la imagen. Sin embargo, ya desde la época clásica y medieval los caligramas habían intentado unir la imagen pictórica y el texto, por ejemplo, en los códices miniados donde la letra inicial buscaba conformar una unidad con el dibujo. A comienzos del siglo XX, los Caligramas de G. Apollinaire inauguraron, desde el surrealismo, un camino de fusión del texto poético con las artes plásticas, que luego fue continuado por otras vanguardias, las cuales enriquecieron la escritura poética predominantemente auditiva con la visualidad del dibujo y la pintura. Esta tendencia continuó en la poesía experimental de los años 60 y 70 y hoy se presenta renovada en la poesía visual con los soportes, que ofrecen la web y los multimedia, el libro objeto y la poesía fonética, donde también interviene la música. Todos son intentos de atravesar las fronteras del signo 
textual convencional, para que diga lo que está más allá de sí a través de otros lenguajes no gobernados por la racionalidad pura sino por la iconicidad simbólica. Por esta razón, en la poesía actual, la lengua conceptual rehúye la sintaxis y los signos de puntuación modificando el lugar de la palabra en el espacio. La experimentación alcanzó niveles muy osados cuando, además, se reemplazó el soporte en papel por otros materiales para trascender los formatos convencionales hasta dar ingreso a la tridimensionalidad con la holopoesía, incorporando así el tiempo subjetivo del lector. En efecto, los holopoemas pretenden romper la fijación, integridad y continuidad del texto, proveyendo una lectura que se da a través de fragmentos vistos por el observador según la posición que éste adopte en relación al objeto. Hoy estamos ante una obra abierta al lector que posee características de interactividad, transitoriedad y multimedialidad: poemas dinámicos que varían de forma, colores, volúmenes y texto dependiendo de la perspectiva espacial del receptor, todo lo cual genera nuevas estrategias de escritura y de lectura (Lamarca Lapuente, 2013). En este tipo de poesía razón y sensibilidad no se presentan enfrentados, sino que se conjugan en un todo regido por el juego de la imaginación. De ahí la libertad en el uso y la disposición de las palabras en el papel. De este modo, imagen y texto se entremezclaban para reforzar una idea o simplemente sugerir otra idea. En el silencio de la pintura y del dibujo, poetas como René Char buscan la desnudez primera de las cosas, la dimensión metapoética (Compagnon, Delon, Marchal, Mélonio \& Noiray, 2007).

La vanguardia pasó, pero quedaron algunas de sus conquistas poéticas, entre ellas, la de este libre jugar con la imagen y la palabra. Hoy ya no hay escuelas literarias en Francia donde ubicar ni a Christophe Lebreton ni a tantos otros. A medida que avanzamos sobre la posmodernidad los poetas se vuelven cada vez más solitarios. En una reciente antología de la poesía francesa actual, Gérard Cartier, compilador y poeta él también, insiste en la presencia de dos constantes que todavía persisten: el tema perenne del amor y la escritura en cuanto a su finalidad y su forma. A ello se suman dos inclinaciones: la fascinación por lo fragmentario y lo inacabado, que se expresa, por un lado, en la dispersión de las palabras sobre la página y, por otro lado, en el recurso a la prosa que se introduce bajo formas muy diversas (Cartier, 2015).

Pues bien, C. Lebreton escribe poesía mística siguiendo esta tradición vanguardista del siglo XX y yendo más allá todavía hasta los umbrales de la hospitalidad posmoderna. La poesía francesa de posguerra, que seguramente debió leer en sus años de estudiante, participaba de este clima de diálogo entre la palabra y el dibujo, entendido como un ejercicio de acceso a lo sacro, a través del cual se buscaba la reverberación de lo esencial, de lo que está más allá de lo dicho. Nuestro monje poeta escribe al modo de 
sus contemporáneos: fusiona texto e imagen, quiebra las fronteras de la gramática, usa los blancos de la página para que el lector pueda respirar, incorpora los espacios vacíos como metáforas del necesario silencio que hay entre las palabras, fragmenta el discurso lógico para que el lector pueda mirar lo que está más allá de la apariencia y realice la experiencia de ver lo invisible en lo visible.

Este estilo poético trabajado en la cotidianidad de una vida monástica abierta al mundo encontró un complemento en la prosa poética de sus diarios, de los cuales sólo se ha publicado este último (Minassian, 2014). A diferencia de la autobiografía, que rememora lo sucedido en el pasado desde el presente, el diario es género del presente que como una cámara busca registrar la verdad de lo que acontece hoy. En el diario de C. Lebreton reconocemos las notas del género íntimo señaladas por Blanchot: "el arraigo en lo cotidiano, el respeto por el calendario que marca el ritmo de la escritura y el carácter necesariamente fragmentario de sus descripciones" (1959: 207-212). Sin embargo, la presencia del Tú divino al que está dirigido el discurso lo acerca al género de la confesión, el cual, inaugurado por san Agustín para mostrar la acción de Dios en su persona, "en nuestros tiempos se ha atrevido a llenar el hueco, el abismo terrible abierto por la enemistad entre razón y vida" (Zambrano, 1995: 24). Pues bien, ¿cuál es el objeto de la confesión en este diario que define como "cuaderno de oración" (Lebreton, 2002: 21)? La acción del Esposo amado que sale al encuentro de la amada que le ha robado su corazón (Ct 4, 9):

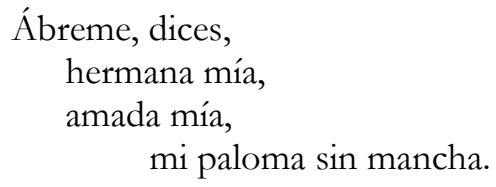

Escribir será

abrirme

He abierto a mi Amado pero dando media vuelta ya ha desaparecido.

Escribir será

buscar, la escritura es herida de un enfermo de amor. (Lebreton, 2002: 20)

En consecuencia, es la alteridad del Tú que en su interior ha puesto su morada la que va configurando la confesión de su identidad. Precisamente en este espacio interior la alteridad ingresa como dinamismo propio de la escritura. En esta experiencia nupcial no hay una subjetividad ensimismada, sino dos personas: el poeta que canta y el Dios hecho Palabra. 


\section{LA HOSPITALIDAD DEL SILENCIO COMO ARCA DE LA ESCRITURA}

La reflexión sobre la escritura es, como señalaba G. Cartier (2015: 11), "el tropismo moderno". El diario comienza con una extensa reflexión sobre el acto de escribir, en el que la página en blanco, los renglones, las palabras entrelazadas entre sí y el silencio, configuran una danza que intenta mostrar el fondo de su experiencia de Dios hecho poesía. El "cuaderno" es descripto como hermoso y festivo porque hablará sobre el Esposo. Además, lo presenta personificado: "te mira" (Lebreton 2002: 25, 9/8/1993). El cuaderno es metáfora de la carne humana sobre la que se va escribiendo día a día nuestra historia, nuestra identidad que no existe a priori, sino que se va configurando a medida que la vamos viviendo y narrando:

Cuaderno grande: qué clase de escritura lo va a llenar.

Escritura con tesón. Te lo ruego.

Transcribir el don día a día.

Eres tú el amigo

Eres tú quien golpea

y me pides abrigo

quieres narrar en mí

una historia

que me sucede. (Lebreton, 2002: 19)

¿Cómo escribir para poder contemplarse en el otro que me habita, de modo que en el distanciamiento se logre configurar la identidad? Escribir es como vivir. Por eso dirá días después: "No es nada: tener un cuaderno. ¿Bien limpio? Cómo hacer. ¿Querrás tomar mi mano, guardándola de todo desvío [...]. Concédeme escribir con precisión" (Lebreton, 2002: 27). La escritura se ha vuelto metáfora de la vida misma. La escritura es como nacer, es dejar salir lo que estaba oculto adentro: pasar de un espacio a otro. La escritura es poder ver y decir que en lo más profundo somos deseo, no por falta de amor sino por exceso, porque la plenitud del amor ya estaba ahí desde el comienzo. Esta escritura es un "juego de amor", una "historia escondida" o "nada de nada" (Lebreton, 2002: 26). ¿Cuál es su contenido? "Eres tú" (Lebreton, 2002: 29). En este contexto existencial la alteridad de quien amando conoce es el único camino hacia la plenitud. Si el tú es la persona del Esposo amado y, en consecuencia, la forma y el contenido de la escritura poética es Cristo, entonces se abre una dimensión eucarística de la escritura: en donación kenótica, Cristo es visto como paradigma de la escritura y del escritor, en tanto Él mismo se da como alimento para que, quien lo recibe, sea transfigurado en vida nueva. 
Al mismo campo semántico del cuaderno y la escritura pertenece la página, el soporte blanco donde la vida acontece narrada. Toda la posibilidad de ser está allí donde: "Me presentas la página. ¿Cómo expresártelo? / Un gran deseo detrás de las palabras que se escriben: verte." (Lebreton, 2002: 25) La página es metáfora de la piel donde se escribe la vida: "(La página se ha estremecido, página prometida)" (Lebreton, 2002: 26). El movimiento de la escritura lo lleva "fuera de la página" "hacia las palabras de otro" (Lebreton, 2002: 19): la escritura trasciende la letra y el papel, trasciende el sentido literal hacia otro sentido a descubrir más allá de lo que simplemente vemos. Por eso M.D. Minassian afirma que:

En la escritura, su lugar de "misión" donde las palabras están hechas para ser entregadas, Christophe hace la experiencia de su "ser para" la epifanía de las palabras a decir y a encarnar. Escribir es revelar. Y revelar es llamar a existir. La escritura permanece en dependencia del Verbo que las desea y del escriba que las consiente (2014: 80).

La primera hospitalidad humana es la de la escucha. El cuaderno, la página en blanco, son metáforas de la escucha que se da en el silencio. Escribir es hacer pasar las palabras de un silencio a otro: del silencio de la meditación, de donde nacen las palabras, al silencio visible de la página que las recibe y las preserva sin que el blanco desaparezca de ella (Chrétien, 1998).

El núcleo del ser revelado es verbal. El poeta lo sabe. Por eso, en una de sus homilías del tiempo de Adviento interpreta con audacia al "Verbo hecho carne" como el "lenguaje hecho hombre" (Lebreton, 2010b: 20). La espera de Dios está puesta bajo el signo de la palabra: "Cuando mi amigo me habla: lo que me dice me toca, me conmueve, me hace bien. Yo lo escucho con todo mi corazón: lo dejo venir a mí... en mí” (Lebreton, 2010b: 20). Precisamente, es esta palabra-llamado del Esposo la que da origen a su experiencia creyente, que es palabra-respuesta que lo abre a la hospitalidad:

Es un Yo te amo que nos mantiene despiertos, es decir, presentes a la realidad, a toda la realidad: la que se ve y la que no se ve. Entonces, vigilar será estar presente al otro, diciéndole sin palabras: yo estoy aquí. Atento a todo lo que en ti es único, a todo lo que en ti está por nacer y crecer... quien está atento... cuida... poniéndose al servicio de Dios (Lebreton, 2010b: 22).

Escribir es una pascua del silencio, un paso del silencio a la palabra. $\mathrm{Y}$, sin embargo, el silencio es un camino que nos dispone a la adoración del Dios que habla y que viene, pero no es el objeto de esa adoración. 
Aclarado lo cual, bien podemos afirmar que la supresión del silencio desertifica la palabra. La hospitalidad del silencio da albergue a la palabra. Jean-Louis Chrétien (1998) considera tres dimensiones del silencio: como escucha, como respuesta y como exceso, que es el silencio místico nupcial. Christophe relacionaba también la escritura con el triple nacimiento del Verbo del que hablaba Tauler: en el Padre, en María, en el hombre: "esta es la dimensión maternal de la escritura" (Lebreton, 2002: 178).

La hospitalidad de su poesía, allí donde su aporte a nuestro hoy es más potente, es justamente este silencio fecundo. "[Las palabras] tú, tú las has dicho. Yo simplemente las capto al acecho en tus labios. Tus ojos me invitan al silencio donde tú las formas. Yo voy a callarme en ti. Abandonar por ti la escritura y salir hacia lo indecible" (Lebreton, 2002: 27-28). No es el silencio como principio originario y absoluto (en alemán, Stille/en griego sigé), sino el silencio como acto (en alemán, Schweigen/ en griego, siopé). Se trata de guardar silencio, dejando que el silencio hospede a la palabra, que sea su "arca" (Chrétien, 1998: 64-65). Esta escritura exige renuncia de sí, vaciamiento, dejarse transfigurar en el dolor: es una escritura crucificada. En el silencio, escritura y carne se vuelven una: "Esta escritura yo la oía, silenciosa, deslizarse en mi carne e inscribirse en ella" (Lebreton, 1997: 39). La palabra, que brota del silencio y acontece en el encuentro interpersonal, pertenece a la lógica de la sobreabundancia. En verso escribe otra homilía en la que propone tener

una mirada silenciosa, pudorosa, humilde, acogiendo, recibiendo el plus del otro (Lebreton, 2010a: 17)

“Acoger" y "recibir" son las palabras con las que J. Derrida se refiere a la acción de la "hospitalidad" propuesta por E. Lévinas:

La acogida no es derivada, no más que el rostro, y no hay rostro sin acogida. Es como si la acogida, al igual que el rostro, al igual que el léxico que le es co-extensivo y por tanto profundamente sinónimo, fuese un lenguaje primero [...]. La acogida determina el "recibir", la receptividad como relación ética. [...] Este recibir, palabra aquí subrayada y propuesta como sinónimo de acoger, sólo recibe en la medida, una medida desmesurada, en que recibe más allá de la capacidad del yo. Esta desproporción disimétrica marcará más adelante, llegaremos a ello, la ley de la hospitalidad. [...] No se puede aprehender o percibir lo que quiere decir recibir sino a partir de la acogida hospitalaria, de la acogida abierta u ofrecida al otro. (Derrida, 1998: 43-44)

"Acoger" y "recibir" son las acciones que elige C. Lebreton para su homilía "poética". La desmesura de la capacidad de recibir que plantea 
Derrida, el poeta la refiere a la sobreabundancia del don que brota de la cruz, en la cual podemos ver y, sobre todo, recibir "el plus del otro": es decir, aquello que él mismo no puede ver por sí mismo, sino que sólo la mirada del amor le puede descubrir. En este hospedarnos unos a los otros consiste la raíz nupcial de todo amor. En revelar esta sobreabundancia originaria del amor radica el sentido último del decir poético en tanto es palabra que hospeda. Este "amor-don", "amor-ofrenda", "amor-loco" es el amor crucificado expresado "en un signo, en un dibujo" (Lebreton, 2010a: 21). Fuerza poderosa de la imagen y la palabra devenidas en lenguaje de la carne.

3. LA HOSPITALIDAD COMO PASCUA NUPCIAL DE LA ESCRITURA: UN ESTILO POSMODERNO DE POESÍA MÍSTICA

¡Vamos! Dejemos hoy decir tu poema. sí, tú me besas hoy con tu boca das tu vida como el Amante da el Beso donde se cumple todo el Don.

(Lebreton, 2002: 125)

Hospitalidad y nupcialidad convertidas en el Poema de Dios. No se trata de una nupcialidad desencarnada sino de una nupcialidad de ojos abiertos, pues la suya es una vida sumergida en la historia: "Asesinatos en Argelia. Se suman a tantos otros. / Este cuaderno no puede quedar al abrigo de esta violencia. Ella me atraviesa" (Lebreton, 2002: 28). Su escritura, su cuerpo, su existencia toda, están insertas en el aquí y ahora.

En el diario evoca esta escena: "Palabras en la huerta (ayer). Mousa: "¿qué te parece, se apaga el fuego con agua o con gasolina?" Yo: "Con agua." M.: "¡Ah, muy bien! Pues mira... Aquí sólo hay Uno que no busca la conquista del poder. Él: Dios” (Lebreton, 2002: 139). Ante la situación límite que viven y el riesgo de morir por ser extranjeros, se plantea el papel de la poesía ante el mal: "Y qué lenguaje vamos a utilizar frente a las palabras asesinas que rechazan al extranjero, al comunista, al francés, al cristiano. ¿La poesía no tendría una palabra - de paz- para cantarla en este campo de batalla?" (Lebreton, 2002: 169). La poesía abre un espacio de paz en tanto, y sólo en tanto, se presenta como lenguaje personal que es acogida en sentido primario: huésped que vaciándose se entrega al otro.

En el mismo año que los monjes trapenses fueron degollados, J. Derrida daba en París un seminario sobre la hospitalidad. Al publicarlo, puso como epígrafe la siguiente afirmación: "Un acto de hospitalidad no puede ser sino poético” (Derrida \& Dufourmantelle, 2000: 10). ¿Qué lazo vincula a la poesía con la hospitalidad? Ambas dicen relación al cobijo de la alteridad, pues ambas beben de la misma gratuidad fontal del ser. ¿Siguen 
siendo experiencias sostenibles hoy? Derrida le negaba a la hospitalidad la incondicionalidad de origen bíblico: en el nivel de las leyes humanas la hospitalidad absoluta le resultaba imposible de sostener (Derrida \& Dufourmantelle, 2000). ¿Qué vuelve sostenible la hospitalidad en la escritura de C. Lebreton? Su carácter nupcial, consumado en la muerte, puede ser tomado como testimonio de que la hospitalidad absoluta es posible. Darse y recibirse en el umbral de la escritura, gestar la palabra fecunda para el hoy, proponer la hospitalidad nupcial como un camino para todos: ello constituye la pascua de su lenguaje. Por ello, al referirse en la misma homilía poética a la acción de acoger en la fe el evangelio de la cruz, dice:

$[\ldots]$ este lenguaje es locura $(1$ Cor 1,18$)$

porque el Amor es loco

esto: los simples, los pobres lo comprenden (Ps 118, 130) porque lo viven.

(Lebreton, 2010a: 20)

La tradición occidental y oriental de la nupcialidad hospitalaria llega a fines del siglo XX hasta la escritura de C. Lebreton, quien la asume y recrea con el lenguaje de vanguardia propio de nuestro tiempo. Para él la habitación nupcial del corazón es la escritura misma: en esto consiste su genialidad y actualidad. Así lo registra en el comienzo de su diario:

Se puede escribir simplemente con un consentimiento silencioso al don: la escritura mariana, es la existencia que corresponde, no sin angustia, no sin dolor., a la Palabra que se cobija aquí, casa carnal.

La escritura estaría habitada

No sin cierta alteración en la sintaxis

O en la ortografía.

La escritura te dejaría ver a ti que vienes incansable, sedienta amante.

La escritura: pesada como mujer encinta, Y dolorosa: en trabajo de parto. (Lebreton, 2002: 27)

La suya es una interioridad que responde al esquema del cubiculum cordis o habitación nupcial del corazón (Chrétien, 2014: 27-50). La expresión latina tiene su origen en aquel pasaje del evangelio de Mateo referido a la oración que dice: "Tú, en cambio, cuando ores, retírate a tu habitación, cierra la puerta y ora a tu Padre que está en lo secreto; y tu Padre, que ve en lo secreto, te recompensará" $(6,6)$. A partir del tratamiento que recibe, primero, por parte de los Padres de la Iglesia, y, luego, por los autores 
medievales, J.L. Chrétien presenta el cubiculum cordis como "una de las figuras espaciales de la interioridad psíquica y espiritual más decisivas y durables en el pensamiento occidental, aun cuando esta afirmación puede sorprender a nuestros contemporáneos, a la mayoría de los cuales le resulta completamente desconocida" (Chrétien, 2014: 30). El quid es el carácter secreto de la habitación, su intimidad, que no está vacía sino habitada por el Tú divino. El corazón, que en sentido bíblico es sede de la identidad personal, refuerza la condición interior de este espacio central para la vida psíquica y espiritual. La palabra griega tamieion utilizada por el texto evangélico indica que se trata de la habitación más interior de la casa. Del latín cubibulum (del verbo cubo, acostarse) se sigue que es el lugar del descanso, de la paz y también de la intimidad amorosa. Es la misma expresión que utiliza en hebreo el Cantar de los cantares $(1,4)$ : la interioridad nupcial exige el corazón de un yo abierto al tú, en hospitalidad recíproca (Moubarac, 1993).

No es un esquema centrado en el propio sujeto que deba construirse a partir de sí, sino un esquema heurístico que explora la presencia de quien lo habita. Se trata de una interioridad en tensión hacia ese Otro que lo ama con la exclusividad inclusiva y la reciprocidad fecundas con que se aman los amantes del Cantar de los Cantares, fuente de toda poesía mística cristiana: por eso es un esquema de interioridad nupcial. C. Lebreton comienza el diario discurriendo largamente sobre la relación entre la "escritura que hospeda" y el "amor nupcial", con lo cual da un giro cualitativo a los temas tratados por sus contemporáneos. Con lo cual ofrece dos aportes: uno formal, la escritura como huésped, el otro, de contenido, la hospitalidad nupcial como fondo ontológico y teologal del amor que triunfa sobre la violencia y la muerte.

El tópico tradicional del cubiculum cordis se desplaza de este modo hacia la escritura, en tanto la Palabra como "casa carnal" puede ser considerada como una recreación de la "habitación del corazón". La nupcialidad se expresa como escritura que manifiesta a la amante sedienta, es decir, a la humanidad que hoy busca insistentemente espacios de intimidad abiertos al tú. Como la mujer, cuyo paradigma es para nuestro poeta la Madre de Dios, la escritura es la que está a punto de dar a luz, con miedo, en la oscuridad del no saber, con el centro en crisis, alterado. Se trata de poder ver: ya no en la transparencia del espejo, sino en la escritura grávida y palpitante de carne viva.

\section{CONCLUSIONES}

"La escritura de Christophe es una palabra habitada, y es esto lo que desea transmitir", acertó en señalar M.D. Minassian (2014: 63). La palabra 
poética se vuelve así portadora del deseo de Dios, en el sentido subjetivo y objetivo del genitivo: Dios nos desea porque ama al ser humano, nosotros lo deseamos como respuesta de amor. No es deseo por carencia, sino por exceso que brota de la experiencia originaria del amor. La poesía de C. Lebreton cumple función de "passeur" cuando vincula amado con amante. Configurada por palabras íntimas y últimas (Minassian, 2014), aquélla es propuesta como carne viva en la que la realidad puede ser expresada y existir de un modo creativo, nunca definitivo, siempre en estado de apertura a nuevas recepciones y recreaciones perfomativas que difieren según los tiempos y los espacios.

Hoy la habitación nupcial del corazón habría que buscarla, pues, en la escritura. No cualquier escritura, sino la "escritura mariana". No cualquier femineidad, sino la de la Madre de Dios, que es nupcial porque en ella se unen lo divino y lo humano, huésped el uno del otro, en reciprocidad de donación y recepción. Escritura como relación y como deseo de Dios. Experiencia existencial del poeta que es teólogo porque habla de Dios, en una escritura en tensión hacia una concordia que, al menos, promete hospedar los opuestos. Así, el aporte de la poesía de C. Lebreton a la tradición milenaria del cubiculum cordis consiste en esta integración entre escritura y hospitalidad nupcial.

"Algo en mi carne ha tomado forma de escritura" (Lebreton, 2002: 3). Este verso sintetiza el estilo de la poesía mística nupcial para el siglo XXI: el cuerpo hecho escritura como origen de la palabra. En este contexto existencial y testimonial proponemos comprender el acto de escribir como espacio poético de nupcialidad y hospitalidad. Esta escritura es búsqueda del Amado ausente, huella de presencia que camina delante, la espalda de Dios que despierta en cada alteridad amada. Quizás, como señaló Bernardo Olivera, la poesía cisterciense como tal no exista, pero hay una y es la de Christophe Lebreton (Olivera, 1997: 11; 2017: 20), quien en ese caso no sería un continuador sino el fundador de un estilo poético posmoderno de escribir nupcialmente sobre la historia del mutuo hospedarse de amor entre Dios y el hombre.

\section{REFERENCIAS}

-Avenatti de Palumbo, C. (2014). “Transcribir un beso". Vigencia de la mística como nupcialidad, escritura y testimonio. Cuadernos de Teología. Mistica y diálogo (6), 8-24.

-Avenatti de Palumbo, C. (2016a). "Entrar en la bodega". Nupcialidad y presencia. La pascua del ver en la poesía de Christophe Lebreton. Taller de Letras NE (4), 97-109. 
-Avenatti de Palumbo, C. (2016b). Poesía y testimonio. El silencio como arca del "ilegible Amor". En C. Avenatti de Palumbo \& A. Bertolini. Dios, el sediento Amante. Nupcialidad, pensamiento y lenguajes (pp. 307-317). Buenos Aires: Agape Libros.

-Avenatti de Palumbo, C. (2016c). "Hay que partir" La hospitalidad como figura y texto de un estilo estético teológico abierto a la comunión. En C. Avenatti de Palumbo \& A. Bertolini (Eds.), El amado en el amante. Figuras, textos y estilos del amor hecho historia (pp. 409-419). Buenos Aires: Agape Libros.

-Avenatti de Palumbo, C. \& Bertolini A. (2015a). La alegría como signo de nupcialidad en tensión escatológica: Christophe Lebreton- Edith Stein. Veritas (32), 37-56.

-Avenatti de Palumbo, C. \& Bertolini A. (2015b). Logos y poesía como acontecimientos del mundo y de la carne: Edith Stein y Christophe Lebreton. Franciscanum (165), 177-200.

-Avenatti de Palumbo, C. \& Bertolini A. (2016). La nupcialidad entre la estética teológica y la ontología trinitaria. Teología (119), 81-11.

-Avenatti de Palumbo, C. \& Bertolini A. (2017a). La casa en el puente. Christophe Lebreton buésped de fronteras. Buenos Aires: Agape Libros.

-Avenatti de Palumbo, C. \& Bertolini A. (2017b). Prólogo a la edición en lengua española. En C. Lebreton. Ama hasta el fin del fuego. Cien poemas de verdad y de vida. (M. Carou, Trad., pp. 9-15), Buenos Aires: Agape Libros.

-Blanchot, M. (1959). El libro que vendrá. Caracas: Monte Ávila Editores.

-Cartier, G. (dir.) (2015). En vivo. Una antología de la poesía francesa actual. Buenos Aires: Leviatán.

-Chrétien, J.L. (1998). L'arche de la parole. Paris: Presses Universitaires de France.

-Chrétien, J.L. (2014). L'espace intérieur. Paris: Les Éditions de Minuit.

-Compagnon, A., Delon, M., Marchal, B., Mélonio, F. \& Noiray, J. (sous la direction de J.Y. Taché) (2007). La littérature française: dynamique et histoire II. Paris: Gallimard.

-Derrida, J. (1998). Adiós a Emmanuel Lévinas. Palabra de acogida. Madrid: Trotta.

-Derrida, J. \& Dufourmantelle, A. (2000). La hospitalidad. Buenos Aires: Ediciones de la flor.

-Francisco, S.S. (2018). Gaudete et exsultate. Sobre el llamado a la santidad en el mundo actual.

http://w2.vatican.va/content/francesco/es/apost_exhortations/documen ts/papa-francesco_esortazione-ap_20180319_gaudete-et-exsultate.html.

-Lamarca Lapuente, M.J. (2013). La fusión entre imagen y texto. En Hipertexto: El nuevo concepto de documento en la cultura de la imagen. Recuperado de http://www.hipertexto.info/documentos/f_imagen.htm.

-Lebreton, C. (1997). Aime jusqu'au bout du feu. Frère Christophe moine-marityr de Tibhirine. Cent poèmes de vérité et de vie. Choisis et présentés par frère Didier. Annecy: Éditions Monte Cristo.

-Lebreton, C. (1999). Le souffle du don. Journal de frère Christophe, moine de Tibbirine. Paris: Centurion. 
-Lebreton, C. (2002). El soplo del don. Diario del hermano Christophe, monje de Tibhirine, 8 agosto 1993-19 marzo 1996. Burgos: Monte Carmelo.

-Lebreton, C. (2009). Adorateurs dans le Souffle. Homélies de frère Christophe Lebreton pourfêtes et solennités (1989-1996). Godewaersvelde: Éditions de Bellefontaine.

-Lebreton, C. (2010a). La table et le pain pour les pauvres. Homélies de frère Christophe Lebreton pour letemps ordinaire (1989-1996). Godewaersvelde: Éditions de Bellefontaine.

-Lebreton, C. (2010b). Lorsque mon ami me parle. Homélies de frère Christophe Lebreton pour Avent/Nö̈l- Carème/Temps Pascal (1989-1996). Godewaersvelde: Éditions de Bellefontaine.

-Lebreton, C. (2017). Ama hasta el fin del fuego. Cien poemas de verdad y de vida. (C. Avenatti de Palumbo \& A. Bertolini, Eds., M. Carou, Trad.). Buenos Aires: Agape Libros.

-Minassian, M.D. (2009). Frère Christophe Lebreton moine de Tibhirine. De l'enfant bienaimé à l'homme tout donné. Godewaersvelde: Éditions de Bellefontaine.

-Minassian, M.D. (2014). De la crèche à la croix. Eléments d'une théologie du don chez. frère Christophe Lebreton, moine de Tibhirine. Fribourg, Suisse: Academic Press.

-Moubarac, Y. (1993). La chambre nuptiale du coeur. Paris: Cariscript.

-Olivera, B. (2011). Martirio y consagración: los mártires de Argelia. Buenos Aires: Claretiana.

-Olivera, B. (1997). Préface. En C. Lebreton, Aime jusqu'au bout du feu. Frère Christophe moine-marityr de Tibhirine. Centpoèmes de vérité et de vie. Choisis et présentés par frère Didier (pp. 10-11). Annecy: Éditions Monte Cristo.

-Olivera, B. (2017). Prefacio. En C. Lebreton, Ama hasta el fin del fuego. Cien poemas de verdady de vida. (M. Carou, Trad., pp. 19-20). Buenos Aires: Agape Libros.

-Olivera, B. \& Silveyra, J.M. (1997). Los mártires de Argelia. Buenos Aires: Paulinas.

-Sussini, M. (2008). Io vivo rischiando per Te. Christophe Lebreton, trappista, martire del XX secolo. Bologna: EDB.

-Vielleux, A. (2002). Un largo poema de amor. En C. Lebreton. El soplo del don. Diario del hermano Christophe, monje de Tibhirine, 8 agosto 1993-19 marzo 1996. (pp. 5-10). Burgos: Monte Carmelo.

-Zambrano, M. (1995). La confesión: género literario. Barcelona: Siruela.

Sumario: 1. Escritura poética y alteridad; 2. La hospitalidad del silencio como arca de la escritura; 3. La pascua nupcial de la escritura: un estilo posmoderno de poesía mística; Conclusiones; Referencias. 